\title{
Relative age and perceptions of soccer specific skills among elite youth players in Norway
}

\author{
Bjørn Tore Johansen ${ }^{1, *}$, Ketil Østrem ${ }^{1}$, Stig Arve Sæther ${ }^{2}$ \& Martin Kjeøen Erikstad ${ }^{1,3}$ \\ 1 University of Agder, Norway \\ 2 Norwegian University of Science and Technology, Norway \\ 3 Nord University, Norway \\ * Corresponding author: Bjørn Tore Johansen, Faculty of Health and Sport, University of Agder, Service Box 422, NO-4604 Kristiansand, Norway, \\ Tel: +4738141295 \\ E-Mail: bjorn.t.johansen@uia.no
}

\section{TARGET ARTICLE}

\section{Article History:}

Submitted $12^{\text {nd }}$ September 2018

Accepted $11^{\text {st }}$ March 2019

Published $6^{\text {th }}$ May 2019

Handling Editor:

Ernst-Joachim Hossner,

University of Bern, Switzerland

Editor-in-Chief:

Martin Kopp

University of Innsbruck, Austria

Reviewers:

Reviewer 1:Werner F. Helsen,

Katholieke Universiteit Leuven,

Belgium

Reviewer 2: Michael Romann,

Eidgenössische Hochschule für Sport

Magglingen, Switzerland

\section{ABSTRACT}

One common feature among the selected players in talent development programs are the wellknown relative age effect (RAE), characterized by a skewed birth distribution among selected players with an over-representation of players born early in the selection year. The aim of the present study was to examine the coaches and players' perceptions of soccer-specific skills between players selected for national talent program born in the first half of the year compared to the players born in the second half of the year. A total of 753 elite male $U 14(N=363)$ and $U 13$ players $(N=390)$ from 16 of 18 soccer regions in Norway participated. The results showed that players born early in the selection year considered themselves stronger and faster than late born players. Similar, coaches considered the players born early in the selection year stronger than players born late in the selection year. Neither the players or coaches considered the early born players as technically, tactically and mentally better. Within a talent development program, we argue that coaches and recruiters should be aware of differences in relative age, and thus prevent that late born players must compensate their physical disadvantages to be allowed into such programs.

Keywords:

Relative age effect - Youth soccer - Player assessed skills - Coach assessed skills

Citation:

Johansen, B. T., Østrem, K., Sæther, S. A. \& Erikstad, M. K. (2019). Relative age and perceptions of soccer specific skills among elite youth players in Norway. Current Issues in Sport Science, 4:006. doi: 10.15203/CISS_2019.006.

\section{Introduction}

A talented player in soccer is often defined as a player who performs better than his/her peers during training and competition, and who has the potential to become a professional player (Helsen, Hodges, Van Winckel, \& Starkes, 2000). Like many other sports, youth soccer competitions are typically organized into annual age groups according to chronological age with specific cut-off dates (Helsen, Baker, Michiels, Schorer, Van
Winckel, \& Williams, 2012). This difference in chronological age is referred to as relative age, and the relative age effect (RAE) in soccer is characterized by a skewed birth distribution among participants within a (selected) age group, with an over-representation of players born early in the selection year (Helsen et al., 2012). Yet, the underlying mechanisms to explain this effect appears less clear, as some argue it mainly exists because talent identification and selection programs identify current performance over potential (Votteler \& Höner, 2014), while others 
argue that it is a result of athletes' experiences with the psychosocial environment (i.e., The Galatea effect, Matthew effect, Pygmalion effect; Eden \& Kinnar, 1991; Hancock, Adler \& Côtè, 2013). Moreover, the prevalence of RAE has not decreased over the last decade and, in fact, there are some evidence that it may have increased even if the research in this area at the same time has augmented (Helsen et al., 2012).

Elite performance in soccer is characterized by a variety of performance parameters, such as technical skills (Ali, 2011) and physical fitness (Stølen, Chamari, Castagna, \& Wisløff, 2005). In terms of relative age, one may naturally expect performance gaps between players within the same age-category, for instance as players born at the end of the year naturally can be expected to be less mature physically (Delorme \& Raspaud, 2009). This assumption has been empirically supported, as it is demonstrated that athletes born earlier in the selection year tend to be taller and heavier than their later born peers (Carling, Le Gall, Reilly, \& Williams, 2009). Moreover, studies have found that relative older players within an age cohort group typically perform better in sprinting and aerobic endurance compared to relative younger players (Figueredo, Gonçalves, Coelho e Silva, \& Malina, 2009; Vaeyens et al., 2006). As coaches and talent scouts traditionally have been likely to favour the physically advanced players (Deprez, et al., 2013), the RAE in youth soccer is often attributed to physical advantages for players born early in the year (Helsen, Starkes, \& van Winckel, 1998; Helsen, van Winckel, \& Williams, 2005).

The physical characteristics (i.e., in height, weight, and/ or strength) can undoubtedly impact young players' perceived potential in soccer (Abbott \& Collins, 2002; Delorme, Boiché, \& Raspaud, 2010; Skorski, Skorski, Faude, Hammes, \& Meyer, 2016), with players born late in the selection year more likely to feel less competent (Delorme, Chalabaev, \& Raspaud, 2011). However, relatively younger players may turn their physical shortcomings into an advantage, as the complexity of soccer can allow players to compensate weaknesses in one area (e.g., speed, strength) with strengths in others (e.g., anticipation, technique; Meylan, Cronin, Oliver, \& Hughes, 2010; Simonton, 2001). Indeed, practice has been identified as the perhaps most crucial factor in the development of sport specific skills (Baker \& Young, 2014). When practicing, relatively younger players may consequently deliberately focus on technical and tactical skill development to compensate for their physical disadvantages compared to relatively older players within a birth cohort. In fact, Cummings et al. (2018) found that later maturing players are more likely to possess and/or develop more adaptive self-regulation skills such as self-evaluation and reflection. Subsequently, when the relatively younger players over time eliminates the gap in physique, having focused on compensating for their physical disadvantages when practicing can result in an advantage. In line with such rationale, Gibbs, Jarvis, and Dufur (2012) identified a relative age effect reversal among the best ice hockey players at elite level, indicating that being born late in the selection year can be positive for athletes' development. Furthermore, while players born at the end of the year are less likely to make the National Hockey League ( $\mathrm{NHL}$; Deaner, Lowen, and Cobley; 2013), Deaner and colleagues found that players born in the last quarter of the year played more games, scored more points, and earned higher salaries than players born in the first quarter of the year. Fumarco, Gibbs, Jarvis, and Rossi (2017) claim that even if the RAE appears to initially favor relatively older players in the minor leagues, if relatively younger players make the $\mathrm{NHL}$, they will likely outperform their peers across several outcomes. Among the NHL elite players, they found that players in the 90th percentile of scoring, those born in the last quarter of the year score about nine more points per season than those born in the first quarter. In addition, elite players in the 90th percentile of salary who are born in the last quarter of the year earn $51 \%$ more pay than players born at the start of the year (Fumarco et al., 2017). Moreover, Fumarco et al. (2017) revealed in their study that compared to players at the lower end of the performance distribution, the RAE reversal is about three to four times greater among elite players. Despite the current results from the RAE reversal effect there is still a need for exploring potential psychological and biological factors explaining this phenomenon.

To adjust to the relative age effect many talent selections programs in several countries around the world (including Norway) have tried to reduce the relative age effect by seeking to identify and develop future senior national players in soccer. In fact, current soccer skills are not a criterion for being selected into the national talent development programme in Norway, as the Norwegian Football Federation (NFF) consider current performance as poor indicators of future performance and may favour players born early in the selection year (NFF, 2018). Rather, the Norwegian model states that selection should be based on players' amount and quality of practice involvement. However, such criterion may be more difficult to assess than soccer-specific skills, and one may expect selected players that are born late in the selection year to have to be either early mature or must compensate their physical weaknesses with strengths in other aspects of soccer skills (e.g., technical, tactical, mental). Although biological factors may have a significant impact on various performance characteristics in youth soccer (Rösch et al., 2000) skill research has shown that the effect of age and maturation is less obvious in skill tests than in physical fitness tests (Eisenmann and Malina, 2003; Malina et al., 2005; Rosch et al., 2000; Vaeyens et al., 2006). As such, Vänttinen, Blomqvist, Nyman, and Häkkinen (2011) reported in a recent longitudinal study that physical fitness of regional soccer players was better than the control groups in all age groups $(11,13$, and 15 years), especially in cardiovascular endurance and in agility, during a two-year monitoring period no differences were found in body composition or serum hormonal levels. Vänttinen et al. (2011) explain these findings by stating that soccer players were more talented by the nature of the game and by the teams' training diaries than age-matched school control groups. Changes in height and body mass are explained by the normal trajectory of growth and maturation that are expected into late adolescence after peak height velocity (Vänt- 
tinen et al., 2011) and are likely influenced by large increases in testosterone after this process. In addition, Cummings and his colleagues (2018) concluded in their study of young English professional soccer academies players that later maturing players appeared to possess a psychological advantage. Subsequently, if talent selection programs identify current performance rather than potential, selected players within the same age cohort should evaluate their soccer skills similar regardless of birth distribution. If such programmes succeed in evaluating potential, relatively younger players may be allowed into the program despite being less skilful at the time of selection.

Therefore, the aim of the present study was to examine potential differences in the perception of soccer-specific skills between players born in the first half of the year compared to the players born in the second half of the year among players selected for the talent identification and development program of the Norwegian Football Federation.

\section{Methods}

\section{Participants}

A total of 753 male athletes from 16 of 18 soccer regions in Norway participated in the study. Participants were selected by the NFF for regional initiatives for males born in 2001 (U-14; $N=$ $363)$ or $2002(U-13 ; N=390)$ and are thereby considered the most talented players in Norway for their respective age categories. On average, athletes began playing organized soccer at $6.0(S D=1.4)$ years of age and were involved in $12.2(S D=$ 5.3) hours of soccer-specific training per week (organized and peer-led practice).

\section{Procedures}

Norwegian Football Federation (NFF) was approached to help recruit athletes, and all regions $(N=18)$ were contacted by email or telephone, invited, and encouraged to participate in the study with athletes selected for male regional U-13 and U-14 teams. An information letter was distributed to players and parents from 16 of 18 regions that agreed to participate. For participating regions, questionnaires, information letters, and a test protocol were distributed to a contact employed in the relevant soccer region. The first data collection was conducted in autumn (approximately mid-October), once the regular soccer season had ended. Under the supervision of a test leader that worked for the relevant soccer region and/or the research group, the paper and pencil questionnaires were completed in a classroom-setting prior to a regional soccer team practice. Completed questionnaires were inserted into sealed envelopes, collected by the test leader, and returned to the last author by mail. Ethical approval was obtained from the Norwegian Social Science Data Services (NSD).

\section{Measures}

Birth-month: Based on previous studies (González-Víllora, Pastor-Vicedo \& Cordente, 2015; Helsen et al., 2005; Musch \& Grondin, 2001) the variables; the date of birth, height, and weight are being used to investigate the presence of RAE in the sample. In accordance with Gonzalez-Víllora et al. (2015) the players were divided into four different birth quarters depending on the month in which they were born: first quarter = January to March, second quarter = April to June, third quarter = July to September, fourth quarter $=$ October to December. The players were also grouped into the 1st half = January to June or 2 nd half $=$ July to December.

Players self-assessed skills: The instrument where players assess their own skill level was developed and validated by Van Yperen (1995). Players were asked to evaluate their own footballspecific skills and competences on a scale from 1 to 10 , where the value 1 is the poorest player in the year class and where the value 10 is the best player in the year class. Van Yperen (1995) developed the original instrument with 14 parts, but the revised edition used in this study consists of seven parts: (1) speed, (2) stamina, (3) muscle strength, (4) technical skills, 5) tactical skills, (6) mental / mental skills, (7) overall assessment as a football player. An example might be: „How do you rate your (muscle) strength as a football player?". The instrument should provide a subjective measurement of players' skill level and it is shown that the instrument has high test - retest reliability, which makes it reliable (Van Yperen, 1995).

Coaches assessment of players skills: The instrument used by the coaches to assess the skill level of players is the same as the players used in their self-assessment of skills, but with another wording: ,His / her (muscle) strength as a football player?".

\section{Statistical analysis}

Differences in birth-date distributions within the sample were tested using chi square statistics. Odds Ratio (OR) with 95\% confidence interval $(\mathrm{Cl})$ were calculated in line with Cobley et al. (2009). Due to the relatively low proposition of players born in the last quarter of the year $(N=81)$ the players were grouped into the first half (January to June), $N=509$, and second half (July to December), $N=242$. To investigate to what extent players born in the first half of the year of the year perceived their own skills differently than players born in the second half an Independent Samples t-test was performed on the variables speed, stamina, muscle strength, technique, tactics, psychological, overall assessment, and potential. The same test was also conducted to investigate whether the coaches rated the soccer-related skills of players born in the first half of the selection year different from players born in the second half. Statistical significance was set at $p<.05$ for all statistical tests. Missing data ranged between 0.2 and $12.6 \%$ across the study variables. 


\section{Results}

The birth distribution of the players in the present sample was: first quarter (January to March), $N=315$, second quarter (April to June), $N=194$, third quarter (July to September), $N=161$, fourth quarter (October to December), $N=81, x^{2}(d f=3)=151$, $p<.01$. OR comparisons using $\mathrm{Q} 4$ as reference group identified OR $3.89(95 \% \mathrm{Cl}=2.63,5.76)$ for Q1, $2.40(95 \% \mathrm{Cl}=1.60,3.58)$ for Q2 and $1.99(95 \% \mathrm{Cl}=1.32,2.99)$ for Q3. OR for first half vs second half were $2.10(95 \% \mathrm{Cl}=1.66,2.66)$. An Independent Samples t-test found $U 14$ players were significantly taller $\left(M_{\text {height }} 171.6 \mathrm{~cm}\right)$ and heavier $\left(M_{\text {weight }} 58.7 \mathrm{~kg}\right)$ than the $U 13$ players $\left(M_{\text {height }} 162.9 \mathrm{~cm}, p<.001, d=0.93 ; M_{\text {weight }} 49.1 \mathrm{~kg}\right.$, $p<.001, d=0.131)$. The U14 players also had a significantly higher number of hours of organized training each week ( $M=7.2$ hours/week) compared to $U 13(M=6.4, p<.001$, $d=0.27)$.

Table 2 shows that early born players considered themselves significantly stronger $(p<.001)$ and faster $(p=.03)$ than late born players, and coaches assessed early born players as stronger than late born players $(p<.001)$

\section{Discussion}

The primary purpose of the present study was to examine the perception of potential differences in soccer-specific skills between players born in the first half of the year compared to the players born in the second half of the year among players selected for the talent identification and development program of the Norwegian Football Federation.

In line with previous studies (Helsen et al., 2012, 2005) players born early in the selection year was overrepresented in the sample that were investigated, with $41.9 \%$ born in the first quarter, $25.8 \%$ born in the second quarter, $21.4 \%$ born in the third quarter, and $10.8 \%$ born in the final quarter of the year ( $p<.01)$. However, in contrast to findings provided by Delorme and co-workers (2011) that players born late in the selection year are more likely to feel less competent, no differences were identified in present study. Nevertheless, relatively older players reported better strength and speed than the younger players. Similar, coaches reported no differences in overall assessment of the players level but reported that older players were stronger than players born in the second half of the year.

Table 1: Overview over height and weight in the population divided in year halves.

\begin{tabular}{llccc}
\hline Age & Variable & 1. Half & 2. Half & $\mathrm{p}$ \\
\hline U 14 & Height & $172.3(7.3)$ & $169.6(9.4)$ & $.009^{* *}$ \\
& Weight & $59.9(7.9)$ & $56.2(8.8)$ & $<.001^{* *}$ \\
U 13 & Height & $164.6(8.9)$ & $159.4(11.9)$ & $<.001^{* *}$ \\
& Weight & $50.4(8.5)$ & $46.8(8.5)$ & $<.001^{* *}$ \\
\hline
\end{tabular}

Note. Values are presented with means and standard deviations (SD). ${ }^{* *}=$ statistical significance at $\mathrm{p}<.01$.

Table 2: Overview over players' and coaches' assessment of the soccer specific skills.

\begin{tabular}{|c|c|c|c|c|c|c|}
\hline \multirow[t]{2}{*}{ Soccer specific skills } & \multicolumn{2}{|c|}{ Player-assessment } & \multirow[t]{2}{*}{$p$} & \multicolumn{2}{|c|}{ Coach-assessment } & \multirow[t]{2}{*}{$p$} \\
\hline & 1. half & 2. half & & 1. half & 2. half & \\
\hline Speed & $7.62(1.51)$ & $7.36(1.59)$ & $.03^{*}$ & $6.30(1.69)$ & $6.09(1.72)$ & .14 \\
\hline Stamina & $7.73(1.40)$ & $7.73(1.40)$ & .98 & $6.41(1.51)$ & $6.30(1.75)$ & .44 \\
\hline Muscle strength & $7.24(1.68)$ & $6.77(1.71)$ & $<.001^{* *}$ & $6.29(1.61$ & $5.77(1.69)$ & $<.001^{* *}$ \\
\hline Technical skills & $7.50(1.66)$ & $7.64(1.55)$ & .29 & $6.19(1.76)$ & $6.28(1.77)$ & .54 \\
\hline Tactical skills & $7.71(1.33)$ & $7.78(1.20)$ & .45 & $6.03(1.72)$ & $5.93(1.75)$ & .47 \\
\hline Mental skills & $7.76(1.35)$ & $7.94(1.29)$ & .09 & $6.17(1.62)$ & $6.00(1.72)$ & .22 \\
\hline Overall assessment & $8.22(0.91)$ & $8.22(0.91)$ & .84 & $6.32(1.53)$ & $6.18(1.58)$ & .25 \\
\hline
\end{tabular}

Note. Values are presented with means and standard deviations (SD). * Significant difference between birth year halves $(p<.05),{ }^{* *}=$ statistical significance at $\mathrm{p}<.01 . *$ 
The findings revealed that early born players considered themselves stronger and faster than late born players. Also, coaches reported that players born in the first half of the year were stronger than players born late in the selection year. Other studies have found that relative older players within an age cohort are faster and have better endurance compared to relative younger players (Figueredo, Gonçalves, Coelho e Silva, \& Malina, 2009; Vaeyens et al., 2006). Players born in the first half consider possessing better physical attributes than late-born players and that early-born players may have higher perceptions of own skills than late born players simply due to their physiological advantages. The present study also documented significant differences in both height and weight between the early-born players and the late born players. While one could have expected that early born players would consider themselves better on all types of soccer skills, as they are relatively older and have had longer time to develop these skills, results revealed no differences on other soccer-related skills (e.g., technical, tactical, and mental skills). Based on the presence of RAE in the present population it is possible that players born in the second half perceive themselves as physically inferior and, thereby, have felt it necessary to develop a unique qualification on other skills, like for example tactical skills, to compete with relatively older and more physiologically mature players. This is in line with Abbott et al. (2002) claiming that the complexity of soccer allows weaknesses to be compensated for by strengthening other skills.

It has been documented that players born early in the year of selection are both taller and heavier than theirs later born co-players (Carling, Le Gall, Reilly, \& Williams, 2009; GonzálezVíllora et al., 2015; Helsen et al., 2005). Results from this study support such discoveries by finding that players born in the first half of the year were significantly taller and heavier than players born in the second half for both $U 14$ and $U 13$ players. However, Deprez, Vaeyens, Coutts, Lenoir, and Philippaerts (2012) have suggested that talent identification and selection program often create homogeneous player groups which possess similar anthropometric characteristics, regardless of in what month the players were born. Indeed, other studies on high-performing sport groups have found no significant differences in the variables height and weight among players born early or late in the selection year (Carling et al., 2009; Deprez et al., 2012; Skorski et al., 2016).

One plausible explanation for the lack of significant differences between players born in the first and in the second half of the year when it comes to their overall assessment of own skills could be that younger players experiencing success by being selected for the regional team and, thereby increase their selfesteem and possibly eradicate the differences between early and late born overestimating their own technical, tactical and psychological soccer skills. Further, based on the findings in Cummings et al. (2018) these late born, and less mature players may have benefit from competitive play with older peers, been more adaptive in self-regulation, and, thereby, developed a psychological advantage. In youth soccer, self-regulation has been shown to assist effective learning, development potential, and differentiate between successful and less successful players (Toering, Elferink-Gemser, Jordet, \&. Visscher, 2009). However, the lack of significant differences may also be due to that late born players selected for the regional teams have entered puberty early and are both taller, heavier, and have more muscles than peers' fellow players who were not selected. This may explain why late born players perceive themselves more comparable the players born earlier in the selection year.

The results of this study indicate that coaches consider players born early in the selection year to be significantly stronger and faster than players born in the second half. Given the importance of these soccer-related characteristics coaches may in general perceive players born early as more talented. Subsequently, the argument put forward by Hancock et al. (2013) that the RAE is enhanced through the Galatea effect/the Pygmalion effect (i.e., RAE because of coaches having higher expectations to early born players) is still relevant. Moreover, players born late are relatively younger, and consequently can be expected to be somewhat less skilled than players who are older if their potential is similar. There was no difference in the coaches' total assessment of soccer specific skills among the players in present study. However, this may indicate that the coaches rather consider present performance over potential in the way that they do not allow relatively younger players to fall behind accordingly in the development of soccer specific skills. Moreover, given the fact that research has documented that physiological and anthropometrical advantages seem to vanish when the period of maturation is over (Cobley, Baker, Wattie \& Mckenna, 2009), and in some sports the reversing of RAE appears when later born players earlier reach a professional level than their earlier born fellow players (Mccarthy \& Collins, 2014). Therefore, in general coaches in youth soccer should be aware of this fact, and, especially, coaches in Norway should for sure be aware of the policy of NFF which clearly states that coaches shall not equal present level of performance with the potential of a player (NFF, 2018). Nevertheless, talent identification is a complicated matter that requires coaches to make subjective judgments of talent that are likely to be influenced by relative age (Mann \& van Ginneken, 2017; Romann \& Cobley, 2015). To minimise the selection-induced RAE one organizes tournaments in Norway for future teams that only consist of late matures or one use 6-months bands rather than 12-months age categories (NFF, 2018). Another possible approach is to age-order the shirt-numbering of the players, and in a study conducted by Mann \& van Ginneken (2017) they demonstrated that the selection bias found as a result of the RAE can be eliminated by ensuring that the shirt numbers worn by junior athletes during competition are ordered according to their age. The finding of this study offers organisations and coaches a simple and practical means of reducing the selection bias associated with RAE in junior team sport. Therefore, the talent identification and development program of NFF ought to identify and evaluate players with potential and the regional coaches' selection should, hopefully, reduce the RAE, and certainly contribute to 
reduce the potential influence of RAE on the perception of soccer specific skills among young selected soccer players.

\section{Strengths and limitations of the study}

This study should be considered for both its strengths and limitations. One of its major strengths was the proportion of the population attained. 16 out of 18 regions participated in the study which means that the sample is highly representative of the total population. A total of 753 selected players from 16 different regions in Norway participated and these players are considered the most talented in their year-class in their region. Thus, the study's population is considered a strength of the study. The variables in this study were based on self-reports. Whether or not the answers are biased because of social desirability or the tendency of respondents to answer questions in a favourable manner remain unknown. The respondents may have answered incorrectly to conform to socially acceptable values, to avoid criticism, or to gain approval (Huang, Liao, \& Chang, 1998). However, socially desirable responding is more likely to occur when the constructs of interest are sensitive (Van de Mortel, 2008). Nevertheless, there is a possibility of systematic bias from socially desirable responses in this study by players assessing their skills to be better than they are due to the social desirability of having good skills and being good at soccer. However, Podsakoff, MacKenzie, Lee, and Podsakoff (2003) have suggested several procedures that can be used to reduce the methodological bias arising from social desirability. The first technique is to assure the respondents that their answers are completely anonymous. The second technique is to make it clear that there are no right or wrong answers and that the respondents should answer the questions as honestly as possible. Both these recommendations were followed strictly in the data collection procedures used in this study. The cross-sectional data in present study prevents any conclusions on the causal relationship between the different variables and, therefore, all causal discussions may only be based on the theoretical foundations. Additionally, given the biological differences in players that likely exist within an annual age category, a limitation of this study was that maturation status was not considered.

\section{Implications}

The findings in this study have documented the presence of RAE among selected players for a national talent development program and thereby contribute with new research on RAE in Norwegian youth soccer. Further, early born players considered themselves stronger and faster than late born players, and coaches considered early born players as stronger. Indeed, as strength and speed are important performance characteristics in soccer (Stølen et al., 2005), relatively older players have an advantage in the selection process if coaches evaluate performance over potential. Additionally, relatively older players have had slightly more time to develop other soccer-related skills (e.g., technique and mental skills). The lack of significant differences in such variables in the present study may indicate that late born players must compensate their physical disadvantages with developing technical and tactical skill to be selected for talent development programs. Consequently, we recommend coaches and practitioners to acknowledge relative age differences within a player age cohort and allow relatively younger players to develop soccer-related skills in an accordingly timeline when aiming to identify potential over current performance. Further, due to the importance of perceiving competence for intrinsic motivation, coaches should have a focus on relatively younger players and encourage them to to control their thoughts, feelings, and actions, including self-initiated processes to convert mental abilities into physical skills in the learning process (Zimmerman, 2006). Young soccer players who self-regulate also approach tasks with a high level of effort and possess increased levels of self-efficacy in general task and will most likely help them to overcome their physical disadvantages, which over time will level out. In sum, an undeniable fact is that the maturation and skill developmental process of a young soccer player is probably more than meets the eye.

\section{Funding}

The authors have no funding or support to report.

\section{Competing Interests}

The authors have declared that no competing interests exist.

\section{Data Availability Statement}

All relevant data are within the paper.

\section{References}

Abbott, A. \& Collins, D. (2002). A theoretical and empirical analysis of a state of the art talent identification model. High Ability Studies, 13, 157-178.

Ali, A. (2011). Measuring soccer skill performance: a review. Scandinavian journal of medicine \& science in sports, 21, 170-183.

Baker, J., \& Young, B. (2014). 20 years later: deliberate practice and the development of expertise in sport. International Review of Sport and Exercise Psychology, 7, 135-157.

Cobley, S., Baker, J., Wattie, N., \& McKenna, J. (2009). Annual agegrouping and athlete development. Sports medicine, 39, 235-256.

Carling, C., Le Gall, F., Reilly, T. \& Williams, A. (2009). Do anthropometric and fitness characteristics vary according to birth date distribution in elite youth academy soccer players? Scandinavian Journal of Medicine \& Science in Sports, 19, 3-9. 
Cumming, S. P., Searle, C., Hemsley, J. K., Haswell, F., Edwards, H., Scott, S., ... \& Cain, A. (2018). Biological maturation, relative age and self-regulation in male professional academy soccer players: A test of the underdog hypothesis. Psychology of Sport and Exercise, 39, 147-153.

Deaner RO, Lowen A, Cobley S (2013) Born at the Wrong Time: Selection Bias in the NHL Draft. PLOS ONE, 8,1-7.

Delorme, N., \& Raspaud, M. (2009). Is there an influence of relative age on participation in non-physical sports activities? The example of shooting sports. Journal of sports sciences, 27, 1035-1042.

Delorme, N., Boiché, J., \& Raspaud, M. (2010). Relative age effect in elite sports: Methodological bias or real discrimination? European Journal of Sport Science, 10, 91-96.

Delorme, N., Chalabaev, A., \& Raspaud, M. (2011). Relative age is associated with sport dropout: evidence from youth categories of French basketball. Scandinavian journal of medicine \& science in sports, 21, 120-128.

Deprez, D., Vaeyens, R., Coutts, A., Lenoir, M. \& Philippaerts, R. (2012). Relative age effect and Yo-Yo IR1 in youth soccer. International Journal of Sports Medicine, 33, 987-993.

Deprez, D., Coutts, A. J., Fransen, J., Deconinck, F., Lenoir, M., Vaeyens, R., \& Philippaerts, R. (2013). Relative age, biological maturation and anaerobic characteristics in elite youth soccer players. International journal of sports medicine, 34, 897-903.

Eisenmann J.C., Malina R.M. (2003). Age- and sex-associated variation in neuromuscular capacities of adolescent distance runners. Journal of Sports Sciences, 21, 551-557.

Eden, D., \& Kinnar, J. (1991). Modeling Galatea: Boosting selfefficacy to increase volunteering. Journal of Applied psychology, 76, 770-780.

Figueiredo, A. J., Gonçalves, C. E., Coelho e Silva, M. J., \& Malina, R. M. (2009). Characteristics of youth soccer players who drop out, persist or move up. Journal of sports sciences, 27, 883-891.

Fumarco, L., Gibbs, B. G., Jarvis, J. A., \& Rossi, G. (2017). The relative age effect reversal among the National Hockey League elite. PloS one, 12(8), e0182827.

Gibbs, B. G., Jarvis, J. A., \& Dufur, M. J. (2012). The rise of the underdog? The relative age effect reversal among Canadian-born NHL hockey players: A reply to Nolan and Howell. International Review for the Sociology of Sport, 47, 644649.

González-Víllora, S., Pastor-Vicedo, J. C., \& Cordente, D. (2015). Relative age effect in UEFA championship soccer players. Journal of human kinetics, 47, 237-248.

Hancock, D. J., Adler, A. L., \& Côté, J. (2013). A proposed theoretical model to explain relative age effects in sport. European journal of sport science, 13, 630-637.

Helsen, W. F., Starkes, J. L., \& Van Winckel, J. (1998). The influence of relative age on success and dropout in male soccer players. American Journal of Human Biology, 10, 791-798.

Helsen, W. F., Hodges, N. J., Winckel, J. V., \& Starkes, J. L. (2000). The roles of talent, physical precocity and practice in the de- velopment of soccer expertise. Journal of sports sciences, 18 727-736.

Helsen, W. F., Van Winckel, J., \& Williams, A. M. (2005). The relative age effect in youth soccer across Europe. Journal of sports sciences, 23, 629-636.

Helsen, W. F., Baker, J., Michiels, S., Schorer, J., Van Winckel, J., \& Williams, A. M. (2012). The relative age effect in European professional soccer: Did ten years of research make any difference? Journal of Sports Sciences, 30, 1665-1671.

Huang, C.-Y., Liao, H.-Y. \& Chang, S.-H. (1998). Social desirability and the clinical

selfreport inventory: Methodological reconsideration. Journal of Clinical Psychology, 54, 517-528.

Malina R.M., Cumming S.P., Kontos A.P., Eisenmann J.C., Ribeiro B., Aroso J. (2005). Maturity-associated variation in sportspecific skills of youth soccer players aged 13-15 years. Journal of Sports Sciences, 23, 515-522.

Mann, D. L., \& van Ginneken, P. J. (2017). Age-ordered shirt numbering reduces the selection bias associated with the relative age effect. Journal of sports sciences, 35, 784-790.

Mccarthy, N. \& Collins, D. (2014). Initial identification \& selection bias versus the eventual confirmation of talent: evidence for the benefits of a rocky road? Journal of Sports Sciences, 32, 1604-1610.

Meylan, C., Cronin, J., Oliver, J., \& Hughes, M. (2010). Talent identification in soccer: The role of maturity status on physical, physiological and technical characteristics. International Journal of Sports Science \& Coaching, 5, 571-592.

Musch, J., \& Grondin, S. (2001). Unequal competition as an impediment to personal development: A review of the relative age effect in sport. Developmental review, 21, 147-167.

NFF; Norwegian Football Federation (2018). Landslagsskolen [The national team school]. https://www.fotball.no/barnog-ungdom/spillerutvikling/landslagsskolen/

Podsakoff, P.M., MacKenzie, S.B., Lee, J.Y., \& Podsakoff, N.P. (2003). Common method biases in behavioral research: A critical review of the literature and recommended remedies. Journal of Applied Sport Psychology, 88, 879-903.

Romann, M., \& Cobley, S. (2015). Relative age effects in athletic sprinting and corrective adjustments as a solution for their removal. PLOS One, 10(4), e0122988.

Rösch D., Hodgson R., Peterson T.L., Graf-Baumann T., Junge A., Chomiak J.,Dvorak J. (2000). Assessment and evaluation of football performance. The American Journal of Sports Medicine, 28, 29-39.

Skorski, S., Skorski, S., Faude, O., Hammes, D., \& Meyer, T. (2016). The relative age effect in elite German youth soccer: implications for a successful career. International journal of sports physiology and performance, 11, 370-376.

Simonton, D. K. (2001). Talent development as a multidimensional, multiplicative, and dynamic process. Current Directions in Psychological Science, 10, 39-43.

Stølen, T., Chamari, K., Castagna, C., \& Wisløff, U. (2005). Physiology of soccer. Sports medicine, 35, 501-536. 
Toering, T. T., Elferink-Gemser, M. T., Jordet, G., \& Visscher, C. (2009). Self-regulation and performance level of elite and non-elite youth soccer players. Journal of sports sciences, 27, 1509-1517.

Vaeyens, R., Malina, R. M., Janssens, M., Van Renterghem, B., Bourgois, J., Vrijens, J., \& Philippaerts, R. M. (2006). A multidisciplinary selection model for youth soccer: The Ghent Youth Soccer Project. British journal of sports medicine, 40, 928-934.

Van Yperen, N.W. (1995). Interpersonal stress, performance level, and parental support: A longitudinal study among highly skilled young soccer players. The Sport Psychologist, 9, 225-241

Van de Mortel, T. F. (2008). Faking it: social desirability response bias in self-report research. The Australian Journal of Advanced Nursing, 25, 40-48.

Vänttinen, T., Blomqvist, M., Nyman, K., \& Häkkinen, K. (2011). Changes in body composition, hormonal status, and physical fitness in 11-, 13-, and 15-year-old Finnish regional youth soccer players during a two-year follow-up. The Journal of Strength \& Conditioning Research, 25, 3342-3351.

Votteler, A., \& Höner, O. (2014). The relative age effect in the German Football TID Programme: Biases in motor performance diagnostics and effects on single motor abilities and skills in groups of selected players. European journal of sport science, 14, 433-442.

Zimmerman, B. J. (2006). Development and Adaptation of Expertise: The Role of Self-Regulatory Processes and Beliefs. In K. A. Ericsson, N. Charness, P. J. Feltovich, \& R. R. Hoffman (Eds.), The Cambridge handbook of expertise and expert performance (pp. 705-722). New York, NY, US: Cambridge University Press. 